\title{
Path Analysis between Organizational Size and Forms of Organizational Commitment
}

\author{
A. Olu Oyinlade*, Zachary J. Christo \\ Department of Sociology \& Anthropology, University of Nebraska, Omaha, NE, USA \\ Email: *aoyinlade@unomaha.edu
}

How to cite this paper: Oyinlade, A. O., \& Christo, Z. J. (2020). Path Analysis between Organizational Size and Forms of Organizational Commitment. American Journal of Industrial and Business Management, 10, 1655-1680.

https://doi.org/10.4236/ajibm.2020.1010105

Received: August 6, 2020

Accepted: October 7, 2020

Published: October 10, 2020

Copyright ( 2020 by author(s) and Scientific Research Publishing Inc. This work is licensed under the Creative Commons Attribution International License (CC BY 4.0).

http://creativecommons.org/licenses/by/4.0/ (c) (i) Open Access

\begin{abstract}
This study attempted to predict the relationship between organizational size and the three established forms of organizational commitment: affective, normative and continuance. We found no statistical evidence or compelling logic to ascertain that organizational size, in itself, will be a meaningful direct predictor of each of the three forms of organizational commitment, and any statistical significance of such relationship would be spurious and meaningless. However, we tested for indirect relationships between size and the commitment variants through five selected mediating variables. We tested the null for three model and 18 path hypotheses using the structural equation model. Our findings showed a fit between our data and model for predicting both affective and normative but not continuance commitment. All 18 path hypotheses were statistically significant as each mediating variable and the commitment variables were predicted by their antecedents. The study showed that perceived firm internal labor market (FILM) upward mobility propensity, voluntary employee organizational involvement, and employee investments in their organizations significantly predicted organizational commitment, especially the affective and normative types.
\end{abstract}

\section{Keywords}

Organizational Size, Organizational Commitment, Affective Commitment, Normative Commitment, Organizational Involvement,

Organizational Investment

\section{Introduction}

This study attempted to empirically understand and explain the likelihood that organizational size, in business organizations, is consequential to different variants of organizational commitment (OC). As indicated by Klein et al. (2009), 
OC was characterized by an employee's sense of attachment to his/her organization. The manifestation of OC among workers may vary depending on social structural context, hence, Meyer and Allen (1991) proposed a three-component model of organizational commitment (affective, normative and continuance) for analyzing and understanding the commitment of organizational members. The three forms of commitment may not be mutually exclusive, as employee behavior may be influenced by the interaction of all three commitment variants within a given context (Meyer \& Herscovitch, 2001). But, despite the likelihood of their mutual inclusiveness tendencies in shaping the behaviors of organizational members, each variant of commitment (with its corresponding antecedents) is important to understand when making decisions that will increase organizational commitment and lower attrition of organizational members.

Among the three variants of commitment, the affective form is characterized by an employee's preference or desire to maintain employment with an organization based on feelings of "affective or emotional attachment to the organization such that the strongly committed individual identifies with, is involved in, and enjoys membership, in the organization" (Allen \& Meyer, 1990: p. 2). That is, affective organizational commitment is the consequence of positive job and nonjob related organizational experiences, as well as psychological and/or emotional affect held by an employee regarding his/her employment relationship with an organization.

In their study, Yang et al. (2004) suggested that affective organizational commitment (AOC) might be predicted by characteristics such as employee values, employee valuation of promotion, and expectations of job security. They found expectations of promotion as an independent significant predictor of AOC in their multiple regression model that included firm internal labor market (the internal job possibilities within an organization) and job promotion expectations as independent variables (Yang et al., 2004). Also, Meyer et al. (2002) highlighted an inverse relationship between AOC and turnover, suggesting that higher levels of AOC were likely to result in less employee turnover. In addition, studies by Islam et al. (2013) and Meyer et al. (2002) suggested that AOC was positively associated with other employee work experiences, such as perceived organizational support, whereby employees who perceived higher levels of organizational support were more likely to be affectively committed to their organizations than employees who perceived lower levels of organizational support. Similarly, positive associations were found between AOC and work experiences including job satisfaction, job performance, and job involvement (Meyer et al., 2002; Aydogdu \& Asikgil, 2011).

Regarding normative organizational commitment (NOC), Meyer and Allen (1991) indicated that this commitment was characterized by an employee's sense of obligation to maintain employment with an organization. The employee who has NOC persists with an organization due to a feeling of indebtedness or obligation to an individual (e.g. a boss) or the organization. This form of commit- 
ment seems more likely to occur within organizational contexts that foster collectivism over individualism, because collectivism generally promotes positive in-group relationships that foster loyalty and feelings of obligations to the group (Meyer \& Parfyonova, 2010).

When the work environment promotes collectivism, employees are likely to feel a sense of support from co-workers, and perceived organizational support had been found to be a direct correlate of NOC (Meyer et al., 2002; Islam et al., 2013). Employees who perceived higher levels of organizational support were found to be more likely to experience NOC than those who perceived lower levels of organizational support (Meyer et al., 2002). Such obligations may reflect one's sense of indebtedness to the organization or a sense of moral duty to retain membership with the organization (Meyer \& Parfyonova, 2010). In addition, there is a positive association between job satisfaction, job involvement, job performance and normative organizational commitment (Meyer et al., 2002).

Literature on continuance organizational commitment (COC) had long indicated that this variant of commitment was characterized by an employee's perceived need to maintain employment with an organization due to perceived high costs associated with discontinuing the employment relationship (Becker, 1960; Meyer \& Allen, 1991). This type of commitment is rooted in Becker's (1960) side-bet theory, which indicated that an individual with continuance commitment had made a side bet when he/she had acted in such a way as to involve his/her nonjob related interests on the basis of cost-benefit analysis, in the decision to remain with an organization. That is, $\mathrm{COC}$ is the result of an employee's continuing employment relationship mainly for his/her other nonjob related interests, and when side-bets favor leaving an organization, the employee would turnover for a more desirable organization (Allen \& Meyer, 1990; Becker, 1960; Meyer et al., 2002).

Continuance organizational commitment (COC) is mainly inversely associated with positive organizational experiences. For example, Meyer et al. (2002) found a weak and inverse association between perceived organizational support, job satisfaction, low turnover rates, high job performance and COC. The reverse expression of these findings suggests that employees who experience low levels of organizational support, poor job satisfaction and poor job performance are likely to persist with an organization rather than quitting if they have COC. The length of such persistence may, however, be conditional on future availability of attractive alternative jobs, because the probability of turnover increases with the presence of attractive job alternatives (Allen \& Meyer, 1990; Becker, 1960; Meyer et al., 2002).

\subsection{Organizational Size, FILM and Organizational Commitment}

Previous research suggests a link between organizational size and characteristics of the firm internal labor market (FILM). Gordon and Thal-Larsen (1969), for example, indicated that organizational size determined the extent to which per- 
sonnel departments would develop within organizations, and Meijaard et al. (2005) found a positive association between firm size and firm complexity measured through departmentalization. The larger an organization becomes, the greater its complexity by number of departments and hence, a larger FILM. This finding appeared persistent across other studies (such as Baron et al., 1986; Yang et al., 2004; Hollister, 2004) that found strong positive associations between organizational size, FILM and promotion ladders in organizations. In addition, Wallace and Kay (2009) found that larger organizations were associated with a larger degree of employee perceptions of ample promotional opportunities.

Other consequences have also been linked to organizational size. Gittleman et al. (1998) indicated that relative to small organizations, large organizations tended to provide greater opportunities for work practices such as cross-training and job rotation, which allowed for greater employee job flexibility. Also, a study by Barber et al. (1999) found that organizational size might be a predictor of organizational hiring practices and employee job search behavior. Larger firms tended to have a more formal and bureaucratic hiring process than do smaller firms, and larger firm sizes tended to attract more job-seekers due to larger job opportunities and career growth in the firm's internal labor market (Barber et al., 1999).

The characteristics of an organization's FILM have consequences for the way jobs are filled by an organization, and for employee attitudes and behaviors. Dating back to about 100 years ago, Sumner Slichter (1919) indicated that hiring practices shaped employee motivation and organizational commitment. He argued that employees who perceived adequate promotion opportunities within their organizations were more likely to be productive and less likely to pursue employment opportunities with other organizations. And, recently, Bidwell and Keller (2014) indicated that the available labor supply in a FILM shaped organizational tendencies to hire from within or to seek external candidates. Job categories which were characterized by higher degrees of performance variability and larger ratios of junior to senior workers tended to be mostly filled via the FILM (Bidwell \& Keller, 2014) which might consequently promote career development and commitment to the organization.

By promoting within the FILM, organizations are able to reduce incentive costs associated with failure to promote junior workers (Bidwell \& Keller, 2014) as well as reduce costs associated with hiring from the outside (Cestone et al., 2018). When organizational expansion necessitates the growth of a given organizational unit, current employees can be quickly moved or promoted, rather than spending precious time and money on the process of hiring external candidates (Cestone et al., 2018). Further, when organizational conditions necessitate the reduction or elimination of any unit, current employees can be reallocated within the FILM instead of being terminated, which can be costly in terms the sunk cost related to any training and development investments in the employees (Cestone et al., 2018). Consequently, organizational FILM provides opportunities for both 
upward mobility and job security, consistently with findings by Hollister (2004) that a higher presence of FILM was associated with higher levels of job security and increased likelihood of employee perceptions of fair reward distributions.

There appears to be an indirect influence of FILM on organizational commitment. In their analysis, Yang et al. (2004) found that FILM was not an independent significant predictor of organizational commitment, suggesting that FILM alone was not enough to elicit feelings of commitment to one's organization. They discovered that after entering the interaction terms into their analysis (FILM $\mathrm{x}$ job security expectation and FILM $\mathrm{x}$ job promotion expectation), both interaction terms were statistically significant, suggesting that the influence of FILM on organizational commitment depended on the extent to which workers valued job security and job promotion (Yang et al., 2004). Therefore, large organizations with their large job markets offer ample opportunities for growth and advancement and, therefore, are more likely to create feelings of organizational commitment for employees who place a higher emphasis on job security and promotion opportunities (Yang et al., 2004).

\subsection{Involvement and Investments}

Job involvement refers to an employee's preoccupation, engagement and concern with his/her job (Paullay et al., 1994). And according to Mgedezi et al. (2014), job involvement might be promoted by the extent to which employees' goals were integrated or consistent with the goals of their organizations. High levels of job involvement have a range of positive outcomes for organizational members, such as employees' perceptions that their jobs are central to their personal character (Hackett et al., 2001), higher levels of effort (Brown \& Leigh, 1996), greater levels of independence and self-confidence (Chen \& Chiu, 2009), and higher levels of job satisfaction and organizational commitment (Nwibere, 2014).

As Harrington and Kendall (2007) indicated, larger firms tended to utilize organizational members from various levels of authority in their strategic goal setting and implementation processes compared to smaller firms. This may mean that employees affiliated with larger firms have the privilege of greater organizational involvement than do employees in smaller firms, and involvement has implications for organizational commitment. Freund (2005) indicated that job involvement was positively associated with affective and career commitment but did not find a significant relationship between job involvement and continuance commitment. However, Meyer et al. (2002) found that job involvement was positively associated with all three variations of organizational commitment (AOC, $r=.53 . p<.05$; NOC, $r=.40, p<.05$; COC, $r=.03, p<.05$ ).

Organizational investments in employee development may also impact organizational commitment. In this regard, Tsui et al. (1997) linked both over-investment and mutual investment with affective organizational commitment. Overinvestment describes an imbalance employee-organization relationship in which "the employee performs only a well-specified set of job-focused 
activities, but the employer offers open-ended and broad-ranging rewards, including training and a commitment to provide the employee with career opportunities" (Tsui et al., 1997: p. 1093). Mutual-investment relationships are characterized by a willingness on the part of both the employee and the organization to contribute to the benefit of the other beyond the specified contractual agreements. It means organizations are willing to offer inducements beyond short term monetary rewards, and employees are willing to consider their organizations' broader interests as important as their specified job tasks. Invariably, both employer overinvestment and mutual-investment relationships produce higher levels of employee performance and affective commitment (Tsui et al., 1997). Also, in their model, Lee and Bruvold (2003) found that when levels of perceived organizational investments in employee development (PIED) were high, job satisfaction and affective commitment were also high, but they found no significant association between PIED and continuance commitment.

\section{Objective}

As indicated in our introductory remarks, the objective of this study was to understand how organizational size might predict each of the three variants of organizational commitment (OC); affective, normative and continuance, established by Allen and Meyer (1990) and Meyer and Allen (1991). These relationships appeared not to have been fully investigated, especially given that many earlier investigations seemed to focus on a general measure of organizational commitment (e.g. Hollister, 2004; Slichter, 1919; Yang et al., 2004) or only one variant of commitment (Oyinlade, 2018). Unlike these previous studies, the objective of this present study is to determine how organizational size simultaneously determines each variant of OC within one structural equation model. In meeting this objective, this study will contribute to literature on factors of organizational commitment by assessing how specified mediating variables between organizational size, measured as number of people in an organizational branch, simultaneously predict affective, normative and continuance forms of organizational commitment. In the process, this study will add knowledge on how organizational size predicts organizational commitment. The study will also shed light on how one same set of factors may serve as antecedent predictors of one another, and of the three variants of organizational commitment.

To accomplish the objective of this study, this article will present knowledge in segments that will consist of a methodology section which will include the design of the study, our research model, model assumptions and research hypotheses. The method section will also include our data collection strategy which comprises of sections on research instrument, survey method and pretest. The rest of the article will include a section on tests and findings with two sub-sections on model results and path results. The remaining divisions in the article will be an elaborate section on discussion and conclusions, and a brief description of the limitations of the study. 


\section{Uniqueness of Present Study}

Our extensive search for literature, specifically on the likely relationship between organizational size and organizational commitment, especially over the past twenty years, yielded only a few studies. Even more scarce, despite our deep search, are related studies over the past five years upon which we could have drawn knowledge and useful directions in conducting this present study. Aside from the studies that we already cited in our review of relevant literature, a few other studies that analyzed the possible role of organizational size in organizational commitment include the analysis of commitment in Mexican Small and Medium-Sized Firms (De clercq \& Rius, 2007) and the mediating role of commitment in the relationship between training approaches and organizational performance among front-line employees in Small-to-Medium Enterprises (SMEs) (Teck-Hong \& Yong-Kean, 2012). Other relevant studies include the role of size in the relationship between organizational rewards and employee commitment in Chinese small and medium-sized enterprises (Newmana \& Sheikh, 2012), the mediation effects of organizational size and tenure in the relationship between organizational justice and organizational commitment (Ohana, 2014), and most recently is the study by Mendoza (2019) that analyzed the likelihood that job satisfaction would predict organizational commitment based on organizational size.

None of the studies mentioned above, however, addressed any area of the questions of our research, and in some cases (e.g. Ohana, 2014; Mendoza, 2019) organizational size was treated as a mediating factor rather than independent (exogenous) factor. And, in the work of Teck-Hong and Yong-Kean (2012), organizational commitment was a mediating factor rather than the outcome variable as designed in the present study. One recent study with some semblance to the present one was the investigation of how job satisfaction predicted organizational commitment among SMEs (Valaei \& Rezaei, 2016). The study used Spector's (1997) nine conditions of job satisfaction (supervision, nature of the work, communication, contingent rewards, co-worker, fringe benefits, payment, promotion and operating procedures) to predict the three variants of organizational commitment in the Information and Communications Technology-Small and Medium-sized Enterprises (ICT-SMEs) in Malaysia.

The Malaysian study (Valaei \& Rezaei, 2016) has a small semblance to the present in that it used the structural equation model to simultaneously analyze the impacts of multiple factors on the three variants of commitment, as in the present study. However, unlike the present study, the Malaysian study focused only on the analysis of how factors of job satisfaction (as independent variables) predicted each variant of commitment in a simple direct model (no mediation). Aside from the simultaneous analysis of the three commitment variants, the Malaysian study did not include any of the variables contained in the present study, and neither did it use multiple stages of mediation as contained in the present study. Also, the Malaysian study, like all other studies reviewed, lacked the anal- 
ysis of organizational size (as a measured continuous variable) through a series of mediation of organizational factors in predicting the three facets of organizational commitment. This means that this present study is unique in its design and it stands to contribute an appreciable amount of knowledge in the understanding of the likely contributions of organizational size to organizational commitment.

\section{Method}

\subsection{Design}

A structural path model was designed to test the paths and the extent to which organizational size would predict the three variants of organizational commitment through five mediating variables. The paths began with organizational size (exogamous independent variable) and consists of three stages of mediation that included five endogamous mediating variables (FILM Perquisites, Perceived FILM Upward Mobility Propensity, Voluntary Employee Involvement in Organization, Employee Investment in Organization, Organizational Investment in Employee) and the three variants of organizational commitment (Affective, Normative, Continuance) as endogamous dependent variables. The list and definition of all study variables are contained in Table 1 .

A total of 19 indirect predictive paths were hypothesized between organizational size and the three variants of commitment (see Figure 1). All the 19 paths were hypothesized to be positive except for the three paths that were hypothesized to predict continuance organizational commitment. Also, no direct paths were hypothesized between organizational size and the commitment variables. This was based on a reasoned assumption that the commitment decision was induced by organizational experiences, and our inability to uncover any evidence and logical support for an assumption that size would be a meaningful direct predictor of commitment. That is, the fact that an organization is large will not be a direct logical reason for members to become committed to the organization, but the experiences and the benefits of size could instigate organizational commitment. This is consistent with findings that experiences of organizational support (Islam et al., 2013; Meyer et al., 2002), opportunities for promotion (Slichter, 1919; Yang et al., 2004; Wallace \& Kay, 2009) and career growth opportunities (Barber et al., 1999) were antecedents of job satisfaction and employee retention. We, therefore, determined that any direct correlation between size and commitment would be spurious and meaningless, but meaningful relationship between the two factors could be established through mediating factors.

\subsection{Model Assumptions}

As stated above, our model assumed that organizational size would not directly predict the variants of organizational commitment, but it would do so indirectly through selected mediating variables. We, therefore, postulated that organizational size had a direct relationship with FILM (see Yang et al., 2004) and this 
Table 1. Definitions and sources of research variables.

Organizational Size: Perceived number of employees in only one's branch or location of an organization. It does not include total number of employees in the total organization when an organization has multiple branches in multiple locations. Size was collected as ratio data but transformed into six ordinal ranks due to extreme variability which produced high standard deviation ( $\mathrm{SD}=1063513)$, skewness (46.98) and kurtosis (2208.4). Post conversion skewness $=-.056$ and Kurtosis $=-1.35$. The conversion to ordinal ranks produced 6 levels of fairly even sizes by percentage: 1 (size = $1-6$ organizational members, $17 \%$ of sample), 2 (size = $7-14$ members, $17 \%$ of sample), 3 (size = $15-25$ members, $17 \%$ of sample), 4 (size = 26 - 49 members, $11 \%$ of sample), 5 (size $=50-150$ members, $22 \%$ of sample) and 6 (size $\geq 151$ members, $16 \%$ of sample).

FILM Perquisite: Perception of the advantage of being able to know about new job openings inside one's organization before the public with, the benefit that the organization prefers to fill positions from within. Author-designed 2 items measured in ordinal ranks, $6=$ Perceived high FILM perquisite, 1 = Perceived low FILM perquisite.

FILM Internal Upward Mobility: Perceptions of the extent to which one believes one can move up one's organizational hierarchy or ladder through timely promotions. Author-designed 9 items measured in ordinal ranks, $6=$ Perceived high internal upward mobility, $1=$ Perceived low internal upward mobility.

Voluntary Organizational Involvement: Perception of extent of voluntary participation in nonjob related social activities in one's organization. Author-designed 4 items measured in ordinal ranks, 6 = high organizational involvement, 1 = Low organizational involvement.

Employee Investment in Organization: Perception of the extent to which one has given of oneself and made sacrifices to one's organization beyond organizationally expected task requirements. Author-designed 7 items measured in ordinal ranks, $6=$ high worker investment, $1=$ low worker investment.

Organizational Investment in Employee: Perception of the extent to which one believes one's organization has made financial investments for one's professional development beyond one's regular income or bonuses. Author-designed 3 items measured in ordinal ranks, $6=$ high organizational investments, 1 = low organizational investments.

Affective Organizational Commitment (AOC): The likelihood that one would remain with an organization for one's love and general positive feeling for current organization. Measured in ordinal ranks, 6 = high affective commitment, 1 = Low affective commitment [Adapted from Meyer and Allen (1997) in Fields (2002), pages 51-53. Meyer and Allen's scale had 8 items, reported alphas ranged from .77 to .88 . The adaptation for this study used 7 of the eight items based on poor factor loading of one item]. See Table 2 for adapted items and factor statistics.

Normative Organizational Commitment (NOC): Persistence with an organization due to a feeling of obligation or indebtedness to current organization. Measured in ordinal ranks, 6 = high normative commitment, 1 = Low normative commitment. [Adapted from Meyer and Allen (1997) in Fields (2002), pages 51-53. Meyer and Allen's scale had 8 items, reported alphas ranged from .69 to .84. The adaptation for this study used 6 of the eight items based on poor factor loading of one item]. See Table 2 for adapted items and factor statistics.

Continuance Organizational Commitment (COC): Persistence (i.e. commitment) to remain with current organization because of fear of not being able to get into a better organization or the high cost one may bear for leaving. Measured in ordinal ranks, $6=$ high continuance commitment, 1 = Low continuance commitment. [Adapted from Meyer and Allen (1997) in Fields (2002), pages 51-53. Meyer and Allen's scale had 8 items, reported alphas ranged from .69 to .84 . The adaptation for this study used 6 of the eight items based on poor factor loading of one item]. See Table 2 for adapted items and factor statistics.

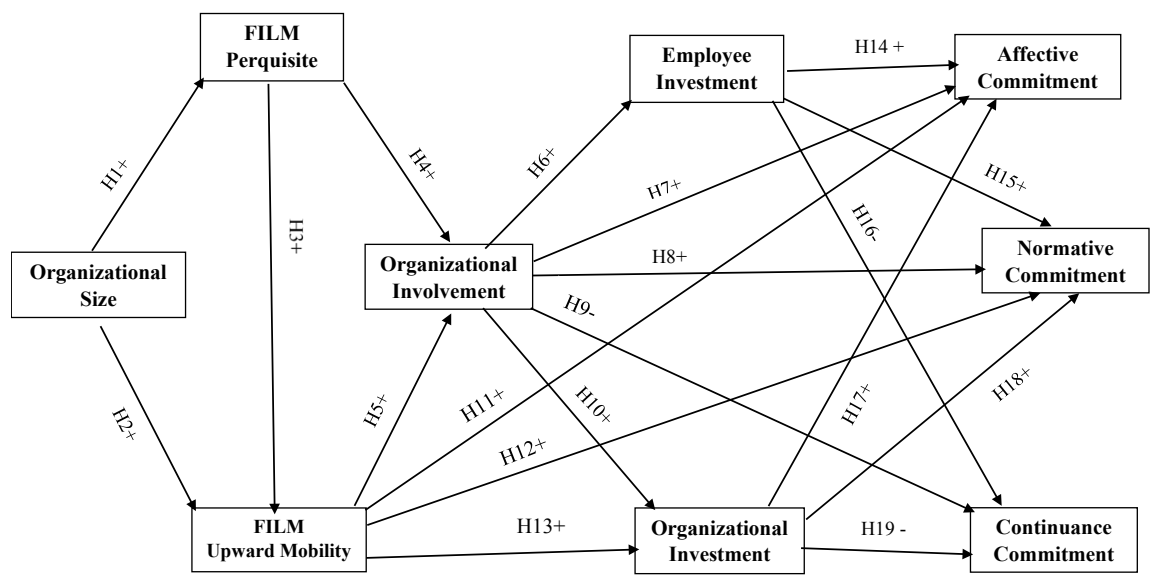

Figure 1. Hypothesized indirect paths between organizational size and variants of organizational commitment. 
could induce employees' higher perceived levels of FILM perquisites and upward mobility propensities. Similarly, to the assumptions of the Two-Factor Theory of motivation (Herzberg et al., 1959), we proposed that high levels of perceived FILM perquisites and propensities for upward mobility would likely reduce employees' levels of organizational dissatisfaction. If dissatisfaction with an organization decreases, it could, logically, enhance voluntary involvement with an organization beyond basic job requirements. These assumptions guided us to hypothesize that higher levels of both FILM perquisites and FILM upward mobility propensity would stimulate voluntary organizational involvements.

If employees are voluntarily involved with their organizations beyond expected job requirements due to lower job dissatisfaction, our model assumed such employees would likely invest themselves in their organizations as well as be willing to make sacrifices (such as spending their free time to participate in non-job activities) for the organization. We equally deduced from voluntary involvement that a highly involved employee would be the type that an organization would prefer to retain, and in whom an organization would, therefore, be likely to invest its resources as rewards to the employee. The logic behind this hypothesized relationship between employee involvement and organizational investments in employees is rooted in the assumptions of instrumentality in the Expectancy Theory of Victor Vroom (see Vroom, 1964).

Our deductive assumptions from voluntary organizational involvement and employee investments in their organizations led us to hypothesize that both factors would positively predict both affective organizational commitment (AOC) and normative organizational commitment (NOC), but negatively predict continuance organizational commitment (COC). This is because both voluntary involvement and employee investments in organization were assumed to be predicated on positive or obligatory feelings for an organization, consistently with the tenets of AOC and NOC, rather than feelings of temporary stay for side-bets associated with COC (Allen \& Meyer, 1990; Meyer \& Allen, 1991).

Lastly, our research framework assumed that organizational investments in employees would positively predict AOC and NOC, but inversely predict COC. This is because we perceived organizational investments in employees as evidence of an organization's interests in developing its employees and possibly retaining them for a long time. In addition, when an organization invests its resources in an employee, it could be based on a real or perceived employee desire to stay and develop a career within the organization. Organizational investments in employees could also positively predict NOC when an employee feels a sense of obligation to persist to avoid guilt that may associate with leaving an organization that had invested much resources in him/her. Consistently with this logic, we further deduced that organizational investments in employees would negatively predict COC, because we assumed that an employee in whom an organization had invested much resources would be less likely to commit to the organization only till a better job becomes available in another organization. The logic that an employee 
in whom an organization has actively invested its resources will stay only till a better offer is received elsewhere, will not be consistent with the assumptions of side-bets (Allen \& Meyer, 1990; Becker, 1960; Meyer \& Allen, 1991) associated with COC. We reasoned, therefore that employees in whom an organization has invested its resources would likely feel gratuitous to the organization, and, therefore, commit for affective reasons (AOC) or feelings of indebtedness (NOC) for receiving much organizational investments.

\subsection{Research Hypotheses}

Based on the assumptions of our analytical model, we advanced the following model hypothesis with three sub-hypotheses and 19 path hypotheses:

\subsubsection{Model Hypotheses}

H1. The research model will likely fit the research data in the plausibility that organizational size will predict the variants of organizational commitment.

H1a: There is a fit between our model and our data in the likelihood of predicting affective organizational commitment (AOC).

H1b: There is a fit between our data and our model in the likelihood of predicting normative organizational commitment (NOC).

H1c: There is a fit between our data and our model in the likelihood of predicting continuance organizational commitment (COC).

\subsubsection{Path Hypotheses}

H1: The greater an organizational size, the greater the level of employee perceived FILM perquisites.

$\mathrm{H} 2$ : The greater an organizational size, the greater the degree of perceived FILM employee upward mobility propensity.

H3. The greater the level of perceived FILM perquisites, the greater the likelihood of perceived FILM employee upward mobility propensities.

H4: The greater the perceived FILM perquisites, the greater the likelihood of voluntary employee organizational involvement.

H5: The greater the perceived FILM employee upward mobility propensity, the greater the likelihood of voluntary employee organizational involvement.

H6: The greater the voluntary employee organizational involvement, the greater the likelihood of employee investment in an organization.

H7: The greater the voluntary employee organizational involvement, the greater the likelihood of affective organizational commitment ( $A O C$ ).

H8: The greater the voluntary employee organizational involvement, the greater the likelihood of normative organizational commitment (NOC).

H9: The greater the voluntary employee organizational involvement, the lesser the likelihood of continuance organizational commitment (COC).

H10: The greater the voluntary employee organizational involvement, the greater the likelihood of organizational investment in an employee. 
H11: The greater the perceived FILM employee upward mobility propensity, the greater the likelihood of affective organizational commitment (AOC).

H12: The greater the perceived FILM employee upward mobility propensity, the greater the likelihood of normative organizational commitment (NOC).

H13: The greater the perceived FILM employee upward mobility propensity, the greater the organizational investment in employees.

H14: The greater the level of employee investments in an organization, the greater the likelihood of affective organizational commitment ( AOC).

H15: The greater the level of employee investments in an organization, the greater the likelihood of normative organizational commitment (NOC).

H16: The greater the level of employee investments in an organization, the lesser the likelihood of continuance organizational commitment (COC).

H17: The greater the level of organizational investments in employees, the greater the likelihood of affective organizational commitment ( $A O C$ ).

H18: The greater the level of organizational investments in employees, the greater the likelihood of normative organizational commitment (NOC).

H19: The greater the level of organizational investments in employees, the lesser the likelihood of continuance organizational commitment (COC).

\subsection{Instrument}

A questionnaire consisting of all nine research variables was constructed for data collection. Except for organizational size, each variable was latent, and hence, measured with observed items. Items for each latent variable were either adapted from previously published works or created by the authors. The list of all research variables, their definitions and sources are presented in Table 1, and items of operationalization of latent variables are on Table 2 and Table 3.

\subsection{Survey}

Data were collected through survey on Mechanical Turk (M-Turk), an Amazon crowd sourcing web platform that allows researchers to get participants for their research for a small fee for each participant, and a service fee for using the platform. For this study, each participant was awarded $\$ 1$ for participation. Participation in a study on M-Turk, such as ours, is voluntary and not based on random selection. We adopted the convenience sampling technique for this study because of the ease of data collection offered by M-Turk and the established high reliability of data collected through this source in other studies such as Gosling, et al. (2004), Ipeirotis (2009) and Paolacci et al. (2010). In addition, M-Turk participants are highly demographically diverse and highly representative of the general US population (Paolacci et al., 2010). Also, the small financial compensation awarded to M-Turk participants had been found by Buhrmester et al. (2011) to not affect data quality.

A total of 2212 participants fully completed the questionnaire for this study. The combination of data from pretest (250 participants) and research surveys 
produced the 2212 participants data set. The average age of the 2212 participants was 33 years and they had worked for their organizations for an average of five years (range $=9: 1$ to 10 years). They were mostly full-time employees (79 percent), non-supervisors/managers (75 percent) and staff employees (67 percent, line $=33$ percent). They were also predominantly racioethnically White non-Hispanic (75 percent) and women (63 percent).

Table 2. Factor components of cross-loading items of latent variables using principal component analysis and equamax rotation method with Kaiser normalization.

\begin{tabular}{llllllllll}
\hline Variables with measurement item & \multicolumn{3}{l}{ Components } \\
\cline { 2 - 8 } & & 1 & 2 & 3 & 4 & 5 & 6 & 7 & 8 \\
\hline
\end{tabular}

\section{FIRM INTERNAL LABOR MARKET UPWARD MOBILITY}

1) My organization has many jobs that provide room to move up the ladder.

2) There are enough jobs in my organization for anyone to stay with the company for ever.

3) My organization has sufficient number of jobs that pay very well at various levels of responsibility.

4) The sky is the limit to how far I can go in my organization.

5) My chances of getting promoted on time are good in my organization.

6) I am optimistic about my opportunities to climb the career ladder in my organization.

7) I am confident about getting my next promotion when I am qualified for it.

8) So long as I continue to do a good job, my promotions will come.

9) My likelihood of moving into higher leadership positions in my organization is good.

\section{EMPLOYEE INVESTMENT IN ORGANIZATION}

1) I have given a great deal of myself to my organization.

2) Anytime I get the chance, I give more of myself to my organization.

3) Beyond my regular tasks, I tend to give my organization all the attention it needs.

4) Beyond my regular tasks, I readily give my energy to my organization.

5) When called upon, I have given much to help advance the cause of my organization.

6) I have given a great deal of my free time to do work related actives.

\section{NORMATIVE ORGANIZATIONAL COMMITMENT}

1) Your feeling of obligation to remain with your current employer

2) Your feeling that it will not be right to leave your organization now, even if it is to your advantage 


\section{Continued}

3) Your feeling of guilt to leave your organization now

4) Feeling that your organization deserves your loyalty

5) A feeling that you are obligated to other people in your organization

6) A feeling that you owe a great deal to your organization

\section{CONTINUANCE ORGANIZATIONAL COMMITMENT}

1) How high is your fear of what may happen to you if you quit your job without having another job lined up first?

.768

.820

so?

3) How high is your feeling that your life will be disrupted too much if you left your organization now? will be scarcity of available job options?

\section{ORGANIZATIONAL INVOLVEMENT}

1)How socially involved are you with people in other departments in your organization?

2) How much do you enjoy participating in social events in your organization?

3) How much do you enjoy voluntarily donating your time to various activities for your organization?

4) How much do you enjoy spending extra time on activities not related to your job, for the benefit of your organization?

\section{AFFECTIVE ORGANIZATIONAL COMMITMENT}

1)Your feeling that you are a "part of the family" in your organization

2) Your feeling that you are emotionally attached to your organization

3) Your feeling that your organization has a personal meaning for you

4) Your feeling of a strong sense of belonging to your organization

\section{ORGANIZATIONAL INVESTMENT IN EMPLOYEE}

1) Reimbursed you for your educational training

2) Paid for you to attend seminars or workshops

3) Paid for you to get some training

\section{ORGANIZATIONAL PERQUISITE}

1) Workers in my organization are the first to know about job openings before they are advertised.

2) My organization prefers to hire internally over hiring from the outside. 
Table 3. Confirmatory factor loadings and Cronbach's alpha for each item of latent variables.

Variables

Comp 1

FIRM INTERNAL LABOR MARKET UPWARD MOBILITY: Cronbach's Alpha $=.960$

1) My organization has many jobs that provide room to move up the ladder.

2) There are enough jobs in my organization for anyone to stay with the company for ever.

3) My organization has sufficient number of jobs that pay very well at various levels of responsibility.

.792

4) The sky is the limit to how far I can go in my organization.

.885

5) My chances of getting promoted on time are good in my organization.

.929

6) I am optimistic about my opportunities to climb the career ladder in my organization.

7) I am confident about getting my next promotion when I am qualified for it. $\quad .914$

8) So long as I continue to do a good job, my promotions will come.

9) My likelihood of moving into higher leadership positions in my organization is good. 915

EMPLOYEE INVESTMENT IN ORGANIZATION: Cronbach's Alpha $=.921$

1) I have given a great deal of myself to my organization.

2) Anytime I get the chance, I give more of myself to my organization.

3) Beyond my regular tasks, I tend to give my organization all the attention it needs.

.881

4) Beyond my regular tasks, I readily give my energy to my organization.

.884

5) When called upon, I have given much to help advance the cause of my organization.

.832

6) I have given a great deal of my free time to do work related actives.

.790

7) I have made a great deal of sacrifices for my organization.

NORMATIVE ORGANIZATIONAL COMMITMENT [NOC]: Cronbach's Alpha $=\mathbf{. 9 4 2}$

1) Your feeling of obligation to remain with your current employer.

2) Your feeling that it will not be right to leave your organization now, even if it is to your advantage.

3) Your feeling of guilt to leave your organization now.

.886

4) Feeling that your organization deserves your loyalty.

5) A feeling that you are obligated to other people in your organization.

6) A feeling that you owe a great deal to your organization.

CONTINUANCE ORGANIZATIONAL COMMITMENT [COC]: Cronbach's Alpha $=.900$

1) Fear of what may happen to you if you quit your job without having another job lined up first

2) Difficulty of leaving your job now, even if you wanted to do so

3) Feeling that your life will be disrupted too much if you left your organization now

4) Feeling that it will be too costly to you to leave your organization now

5) Feeling of having too few options than to consider leaving your organization

6) Feeling that a serious obstacle to leaving your organization now is scarcity of available job options

VOLUNTARY ORGANIZATIONAL INVOLVEMENT: Cronbach's Alpha $=.910$

1) Social involvement with people in other departments in your organization.

2) Enjoy participating in social events in your organization.

3) Enjoy voluntarily donating time to various activities for your organization.

4) Enjoy spending extra time on activities not related to your job, for the benefit of your organization.

.900

AFFECTIVE ORGANIZATIONAL COMMITMENT [AOC]: Cronbach's Alpha $=.953$

1) Your feeling that you are a "part of the family" in your organization.

2) Your feeling that you are emotionally attached to your organization.

3) Your feeling that your organization has a personal meaning for you.

4) Your feeling of a strong sense of belonging to your organization.

ORGANIZATIONAL INVESTMENT IN EMPLOYEE: Cronbach's Alpha $=.892$

1) Reimbursed you for your educational training.

2) Paid for you to attend seminars or workshops.

3) Paid for you to get some training.

ORGANIZATIONAL PERQUISITE: Cronbach's Alpha $=.775$

1) Workers in my organization are the first to know about job openings before they are advertised. 904

2) My organization prefers to hire internally over hiring from the outside. 


\subsection{Pretest}

First, all the scales of all latent variables were factor analyzed for reliability and validity. The exploratory factor analysis (EFA) using Principal Component Analysis and Equamax Rotation Method with Kaiser Normalization was conducted to determine cross-loading items, and any item that highly cross-loaded (with factor value above .50) on more than one factor was eliminated from the scale. All remaining items for final analysis loaded highly only on their respective factor components (see Table 2). The Cronbach's alpha and the confirmatory factor analyses (CFA) were also conducted on each scale for construct validity (see Table 3). Cronbach's alphas for all variables ranged from .775 to .960 , and the coefficients of all scale items loaded highly only on their respective factor components. The loading coefficients for every observed item in each scale exceeded .700, indicating a strong internal consistency and construct validity among the items for each latent variable (Table 3). Also, a correlation matrix was conducted among all the research variables (see Table 4), and no sign of multicollinearity was detected, as no two variables had an extremely high correlation (such as exceeding .90) which could call for analysis of tolerance and variance inflation factor. The correlation matrix included a test of direct correlation between organizational size and the three variants of organizational commitments. Consistently with our analytical model assumption relating to the relationship between size and commitment, our correlation test (see Table 4) yielded no significant relationship between size and AOC and very week correlations with NOC $(r=.050)$ and $\operatorname{COC}(r=.069)$.

\section{Test and Findings}

The structural equation model (SEM) was used to test our null for the model hypotheses and the 19 path hypotheses with the aid of Analysis of Movement

Table 4. Correlation matrix among all variable.

\begin{tabular}{|c|c|c|c|c|c|c|c|c|}
\hline & 1 & 2 & 3 & 4 & 5 & 6 & 7 & 8 \\
\hline 1) Organizational Size & 1 & & & & & & & \\
\hline 2) FILM Perquisite & $.090^{* *}$ & 1 & & & & & & \\
\hline 3) FILM Upward Mobility & $.151^{* *}$ & $.492^{* *}$ & 1 & & & & & \\
\hline 4) Organizational Involvement & -.006 & $.343^{* *}$ & $.463^{* *}$ & 1 & & & & \\
\hline 5) Employee Investment & .011 & $.171^{* *}$ & $.239^{* *}$ & $.424^{* *}$ & 1 & & & \\
\hline 6) Organizational Investment & $.080^{* *}$ & $.318^{* *}$ & $.490^{* *}$ & $.385^{* *}$ & $.217^{* *}$ & 1 & & \\
\hline 7) Affective Commitment & -.006 & $.386^{* *}$ & $.511^{* *}$ & $.633^{* *}$ & $.442^{* *}$ & $.406^{* *}$ & 1 & \\
\hline 8) Normative Commitment & $-.050^{* *}$ & $.321^{* *}$ & $.443^{* *}$ & $.536^{* *}$ & $.417^{* *}$ & $.333^{* *}$ & $.735^{* *}$ & 1 \\
\hline 9) Continuance Commitment & $.069^{* *}$ & .012 & $-.063^{* *}$ & -.006 & $.150^{* *}$ & -.017 & $.041^{*}$ & $.165^{* *}$ \\
\hline
\end{tabular}

**. Correlation is significant 0.01 (1-tailed). ${ }^{*}$ Significant at 0.05 (1-tailed). 
Structures (AMOS) program. For ease of fitting all the research variables into our model, the observed variable path analysis (OVPA) was adopted, therefore, all latent variables were entered into our structural equation in their observed (manifest) forms determined through factor analysis. At first run, the obtained indices for goodness of fit were poor, indicating a poor fit between our model and data. We, then, used the output modification indices suggested by AMOS to adjust the path analyses by correlating the variable errors between the three dependent variables, and eliminating the hypothesized path between organizational investment in employee and organizational continuance commitment. The modified model was then analyzed, and results showed a strong fit between our model and data.

\subsection{Model Results}

Test results for our adjusted model (Figure 2) demonstrated a good fit between our default model and data based on our obtained absolute goodness of fit indices $\left(\chi^{2}=147.412, d f=(54-38) 16, p=.000\right.$; root mean square error of approximation $($ RMSEA $)=.061)$. Although, RMSEA of .05 or less is preferred (Steiger, 2000), our obtained value of .061 is fully acceptable since RMSEA value is acceptable up to .080 (see Browne \& Cudeck, 1993; Hu \& Bentler, 1995). Also, for a model fit, the $p$-value for our default model chi-square (the discrepancy function value) should be higher than .05 for the model to be acceptable, hence, demonstrating that the observed covariance matrices of the default and saturated (predicted) models are similar. That is, the observed covariances of the default model and the saturated model should not be significantly different from each other for a model to be acceptable. However, when sample size is large (typically greater than 200), the requirement for the Chi-square $p$-value to be higher than .05 is waived (Arbuckle \& Wothke, 1999; Hooper et al., 2008). This is because when sample size is large, Chi-square $p$-value will most often be less than .05 , and hence, rejecting a model by indicating a significant difference between the covariance matrices of the default and saturated models (Arbuckle \& Wothke, 1999; Hooper et al., 2008). With a large sample size, the $p$-value condition is also waived if other model fit indices indicate that a model is acceptable ( $\geq .90)$ (Byrne, $1994)$ or very strong ( $\geq .95)$ (Schumacker \& Lomax, 2004). Given our large sample size $(N=2212)$ and strong model fit values (below), our model was deemed acceptable as a plausible explanation for our outcome variables.

Our model fit analysis showed that the incremental model fit indices (baseline comparison values) were very strong: Relative Fit Index $(\mathrm{RFI})=.945$, Normed Fit Index $(\mathrm{NFI})=.976$, Comparative Fit Index $(\mathrm{CFI})=.978$, Tucker-Lewis Index $(\mathrm{TLI})=.951$ and Incremental Fit Index $(\mathrm{IFI})=.978$. Based on these values, the null for the model hypothesis (H1) was rejected. The model (as adjusted) did fit the data, indicating that organizational size was a plausible indirect explanation for the three forms of organizational commitment through the chain of hypothesized relationships among our specified mediating variables. 


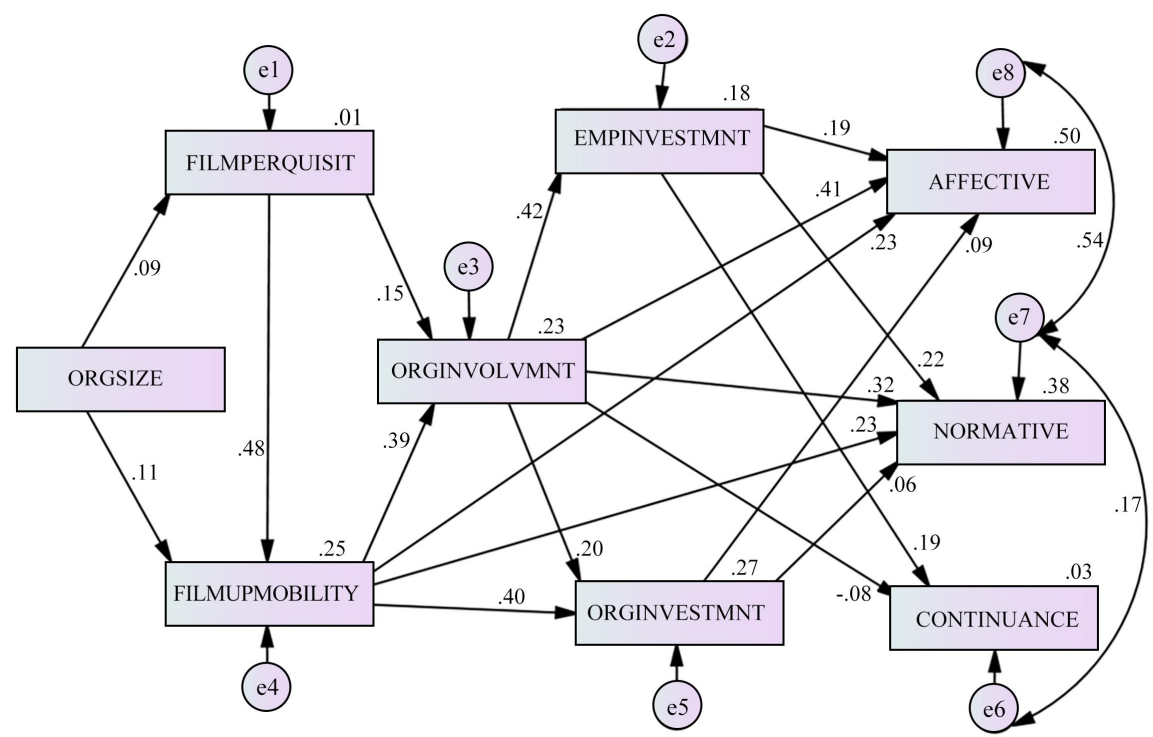

Figure 2. Standardized beta coefficients and $R^{2}$ values for all hypothesized paths between organizational size and organizational commitment in the adjusted model.

The decision for the null for the three model sub-hypotheses required the assessment of the product of all the statistically significant paths among the mediating variables leading to each variant of commitment. Results of the SEM (Table 5) showed that our hypothesized paths predicted both affective organizational commitment (indirect effect $\beta=.077, R^{2}=.50, p=.000$ ) and normative organizational commitment (indirect effect $\beta=.068, R^{2}=.38, p=.035$ ), but not continuance organizational commitment (indirect effect $\beta=.000, R^{2}=.03, p=.071$ ). These findings indicate that our model paths are plausible for the likelihood that organizational size would contribute to the variability in, as well as predict AOC and NOC, but not COC through our specified paths of mediating factors (Table 5). These results led to the rejection of the null for the first two model sub-hypotheses (H1a and H1b), while the null for the third model sub-hypothesis (H1c) failed to be rejected.

\subsection{Path Results}

The findings of our SEM showed statistically significant causal relationships among the research variables as hypothesized in the 18 paths in our adjusted model (Table 6 and Figure 2). Organizational size and each mediating variable were significant antecedent predictors of an outcome variable, hence, the null hypothesis for each of the 18 paths was rejected. This indicates that each hypothesized path from organizational size to a variant of organizational commitment was a plausible explanation and predictor of an outcome (endogenous) variable leading to a commitment variant.

Details of the results of our path analysis are presented in Table 6 and Figure 2 , hence, we focus on key findings in this section. The path analysis results showed that our adjusted model indicated that the three variants of organizational commitment were significantly predicted by their antecedent path factors. 
Table 5. Intercepts, squared multiple correlations $\left(R^{2}\right)$ and total coefficients of indirect effects of organizational size on all mediating and dependent variables.

\begin{tabular}{|c|c|c|c|c|c|c|}
\hline & Constance & S.E. & C.R. & $R^{2}$ & $p$ & Indirect Effects \\
\hline FILM Perquisite & 7.719 & .130 & 59.603 & .01 & .000 & .000 \\
\hline FILM Upward Mobility & 8.617 & .839 & 10.265 & .25 & .000 & .044 \\
\hline Organizational Involvement & 5.907 & .336 & 17.556 & .23 & .000 & .072 \\
\hline Organizational Investment & 2.864 & .269 & 10.657 & .27 & .000 & .074 \\
\hline Employee Investment & 22.045 & .390 & 56.478 & .18 & .000 & .031 \\
\hline Affective Commitment & 23.036 & .629 & 36.611 & .50 & .000 & .077 \\
\hline Normative Continuance & -.830 & .934 & -2106 & .38 & .035 & .068 \\
\hline Continuance Commitment & 1.120 & .621 & 1.803 & .03 & .071 & .000 \\
\hline
\end{tabular}

Table 6. Maximum likelihood estimates of both unstandardized and standardized regression coefficients for the modified (final) path analysis.

\begin{tabular}{|c|c|c|c|c|c|c|c|}
\hline \multicolumn{3}{|c|}{ ADJUSTED MODEL REGRESSION PATHS } & \multirow{2}{*}{$\begin{array}{c}\text { b } \\
.140\end{array}$} & \multirow{2}{*}{$\begin{array}{l}\text { S.E. } \\
.033\end{array}$} & \multirow{2}{*}{$\begin{array}{l}\text { C.R. } \\
4.263\end{array}$} & \multirow{2}{*}{$\begin{array}{c}\boldsymbol{\beta} \\
.090\end{array}$} & \multirow{2}{*}{$\begin{array}{c}p \\
* * *\end{array}$} \\
\hline FILM PERQUISIT & $\leftarrow$ & ORG SIZE & & & & & \\
\hline FILM UPMOBILITY & $\leftarrow$ & FILM PERQUISIT & 2.231 & .085 & 26.126 & .482 & $* * *$ \\
\hline FILM UPMOBILITY & $\leftarrow$ & ORG SIZE & .768 & .132 & 5.818 & .107 & $* * *$ \\
\hline ORG INVOLVMNT & $\leftarrow$ & FILM UPMOBILITY & .167 & .009 & 18.156 & .389 & $* * *$ \\
\hline ORG INVOLVMNT & $\leftarrow$ & FILM PERQUISIT & .303 & .043 & 7.105 & .152 & $* * *$ \\
\hline EMP INVESTMNT & $\leftarrow$ & ORG INVOLVMNT & .596 & .027 & 21.985 & .424 & $* * *$ \\
\hline ORG INVESTMNT & $\leftarrow$ & ORG INVOLVMNT & .183 & .019 & 9.799 & .201 & $* * *$ \\
\hline ORG INVESTMNT & $\leftarrow$ & FILM UPMOBILITY & .156 & .008 & 19.371 & .397 & $* * *$ \\
\hline NORMATIVE & $\leftarrow$ & ORG INVESTMNT & .098 & .033 & 2.930 & .057 & .003 \\
\hline CONTINUANCE & $\leftarrow$ & ORGI NVOLVMNT & -.113 & .031 & -3.665 & -.085 & $* * *$ \\
\hline CONTINUANCE & $\leftarrow$ & EMP INVESTMNT & .176 & .022 & 8.012 & .185 & $* * *$ \\
\hline AFFECTIVE & $\leftarrow$ & EMP INVESTMNT & .152 & .013 & 11.615 & .194 & $* * *$ \\
\hline NORMATIVE & $\leftarrow$ & EMP INVESTMNT & .242 & .021 & 11.701 & .217 & $* * *$ \\
\hline NORMATIVE & $\leftarrow$ & ORG INVOLVMNT & .500 & .032 & 15.463 & .318 & $* * *$ \\
\hline NORMATIVE & $\leftarrow$ & FILM UPMOBILITY & .154 & .014 & 11.217 & .227 & $* * *$ \\
\hline AFFECTIVE & $\leftarrow$ & FILM UPMOBILITY & .110 & .009 & 12.486 & .230 & $* * *$ \\
\hline AFFECTIVE & $\leftarrow$ & ORG INVOLVMNT & .454 & .021 & 22.103 & .410 & $* * *$ \\
\hline AFFECTIVE & $\leftarrow$ & ORG INVESTMNT & .114 & .021 & 5.333 & .094 & $* * *$ \\
\hline
\end{tabular}

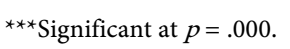

The model (Table 6 and Figure 2) indicated that the strongest predictor of affective organizational commitment (AOC) was voluntary organizational involvement $(\beta=.41)$ followed by FILM upward mobility propensity $(\beta=.23)$, while organizational investment in employee was the weakest predictor $(\beta=.09)$, albeit statistically significant. Our SEM findings also indicated that normative organizational commitment (NOC) was most strongly predicted by voluntary 
organizational involvement $(\beta=.32)$, then FILM upward mobility propensity $(\beta=.23)$ and employee investment in organization $(\beta=.22)$, while organizational investment in employee was the weakest predictor $(\beta=.06)$. For continuance organizational commitment (COC), our model showed employee investment in organization as the stronger predictor $(\beta=.19)$ while voluntary organizational involvement was a weaker and inverse predictor $(\beta=-.08)$ of this variable.

Among all the antecedents of each variant of organizational commitment, voluntary organizational involvement was the strongest single predictor of two variants (AOC, $\beta=.41$; NOC, $\beta=.32$ ) while employee investments in organization was the stronger predictor of $\operatorname{COC}(\beta=.19)$. In total, all the hypothesized 18 causal paths produced significant positive results except the path between organizational involvement and COC as predicted in the analytical model. However, it was predicted in the model that employee investment in organization would negatively predict COC, but our finding indicated a positive relationship $(\beta=.19)$. A possible explanation for this opposite direction is given in the summary and conclusion section (below).

\section{Discussion and Conclusion}

This study was designed to investigate the likelihood that organizational size would predict the three variants of organizational commitment propounded and popularized by Meyer and Allen (1991, 1997). Following our assumption and correlation result that indicated that organizational size was not a meaningful direct predictor of organizational commitment, we advanced five mediating variables through 19 predictive paths that would demonstrate how organizational size might indirectly predict organizational commitment. These paths were based on several logical assumptions rooted in many earlier studies (such as Baron et al., 1986; Gordon \& Thal-Larsen, 1969; Hollister 2004; Meijaard et al., 2005; Yang et al., 2004) that organizational size, while not a direct predictor of organizational commitment, was a positive predictor of organizational complexity. Typically, when complexity is high, size is large (Gordon \& Thal-Larsen, 1969; Hollister, 2004; Meijaard et al., 2005) and so is FILM, which is a source of opportunities for organizational members to achieve growth through promotions, as well as serve as a source of hope for future promotions. Therefore, indirectly through the benefits of size, organizational members may commit to their organizations.

Based on our model, we structurally analyzed the likelihood that our five mediating variables would predict the likelihood of the three forms of organizational commitment. Using SEM, our findings indicated a strong fit between our data and our model for affective organizational commitment (AOC) and normative organizational commitment (NOC). For this fit to occur, however, AMOS required that one of our hypothesized paths between organizational investment in employee and continuance organizational commitment (COC) be dropped for lack of fit between data and this path. The adjusted model reduced our path analysis by one, but the remaining 18-path model was statistically predictive of only AOC and NOC, but not COC. 
Findings of this study mostly align with the directions of our hypothesized predictive relationships for all endogamous variables including the three commitments variants, except the positive value between employee investments in organizations and $\operatorname{COC}(\beta=.19)$ which was hypothesized to be negative in our deductive logic. One plausible explanation for this finding could be that when employees remain with their organizations for continuance reasons (until a better job becomes attainable), they may invest themselves in their present jobs and organizations for the purpose of boosting their credentials, and for getting good references from their current employments to enhance their abilities to enter other organizations when exiting their current ones.

Our results were consistent with those of some other studies that had attempted to predict different forms of commitment. For example, we found, consistently with Meyer et al. (2002) that voluntary organizational involvement positively predicted AOC $(\beta=.41)$ and NOC $(\beta=.32)$ and very week in predicting COC $(\beta=-.085)$. But unlike Freund (2005) who did not find a significant predictive relationship between voluntary organizational involvement and COC, we found the relationship to be significant, albeit that the standardized coefficient was negative and very low. These findings could be interpreted, consistently with our logical assumptions that voluntarily involved employees would likely develop positive feelings toward their organizations, and hence, become more likely to commit for affective reasons and less likely to commit for side-bets reasons, consistently with the inverse relationship result with COC. The finding that voluntary organizational involvement positively predicted NOC may be understood within the assertion that normative commitment is associated with perceived climate of organizational support and organizational collectivism (Meyer et al., 2002; Islam et al., 2013). And, given that organizational support and collectivism would likely foster involvement, it becomes plausible that organizational involvement would produce a commitment based on obligations to the organization (NOC).

Our findings that FILM upward mobility propensity significantly predicted the likelihood of both AOC and NOC were not surprising. Theories of motivation such as the Hierarchy of Needs Theory (Maslow, [1943] 2013), Existence Relatedness Growth (ERG) Theory (Alderfer, 1972) and Hygiene-Motivation Theory (Herzberg et al., 1959) have indicated that real or perceived opportunities for upward mobility predicted the likelihood of higher job performance among organizational members. By extension, the positive perceptions of the likelihood of upward mobility could serve as the basis for the decision to stay with an organization, either because of intrinsic satisfaction from upward mobility (hence, AOC) or because of feelings of obligation to stay, and/or to avoid guilt for leaving an organization that has provided growth opportunities (and hence, NOC). Regardless whether it is AOC or NOC, our results show that the perception of opportunities to move up in a FILM is a strong basis for organizational commitment. This signals the importance of organizational design that fosters upward mobility for employees, and organizational executives could be re- 
minded by these findings to include employee upward mobility considerations in their efforts to redesign their organizational structures to enhance both higher job performance and organizational commitment.

We also found that mutual investments in each other between employees and their organizations predicted all three forms of commitment as we hypothesized in our predictive paths. We found employees that invested themselves in their organizations to be likely to have a higher level of NOC $(\beta=.22)$ than AOC $(\beta=.19)$ and $\operatorname{COC}(\beta=.19)$. But, when employees perceived a high level of organizational investments in themselves, such perceptions were found to be a weak predictor of all commitment variants. In fact, we found this variable to be the weakest predictor of all commitment variants (AOC, $\beta=.09$; NOC, $\beta=.06$; and $\mathrm{COC}$ was eliminated for poor fit). That is, organizational investments in employees is a very weak independent predictor of each variant of organizational commitment. This could mean that organizational investments in employees are perceived (by employees) as deserved and earned benefits for their hard work, rather than as inducements for future commitments. This could, therefore, imply that organizational investments in employees are less important in garnering employee commitment than employee investments in their organizations. When employees make personal sacrifices beyond job expectations for their organizations, they seem to be more likely to stay, than when it is their organizations that invested in them. However, given that employees' investments in organizations more strongly predicted NOC than AOC, it appears that such investments were likely based mainly on feelings of obligation rather than affinity for the organization.

While organizational investments in employees might be good for other reasons (such as improving employees' performance effectiveness, developing leadership potentials and enhancing career development), they may not serve as a reliable source for getting employee commitment to the organization based on the findings of this study. It would, therefore, be best for organizational executives to restructure their organizational processes to induce greater employee involvements and investments to promote AOC and NOC (especially when AOC is preferred over NOC).

\section{Limitations}

While several studies have been done on organizational commitment, every study is limited in generalization based on variables included in each study model. It means, therefore, that this present study is generalizable only within the variables analyzed and, to a large extent, only to the study participants because of the adopted nonrandom sampling method.

It is also important that the weak predictive relationship between organizational investments in employee and AOC and NOC be further investigated as logic would lead one to assume stronger relationships than found in this study. This is especially important for AOC because logically, one would expect em- 
ployees to value organizational investments in themselves, unless such investments are perceived negatively or with poor value, as indicated by the Expectancy (Valence) Theory of motivation (Vroom, 1964).

If organizational investments in employees carry high value for the employees, it becomes reasonable to postulate that such investments would, at the very least, produce feelings of obligations which may result in normative organizational commitment in return for the investments. And, at the very best, the investments in employees could yield AOC for feelings of appreciation of the investments. Perhaps, as indicated by Meyer and Herscovitch (2001), a thorough understanding of organizational commitment might require a commitment profile which describes the subjective combination of employees' feelings of affective, normative, and/or continuance commitment within a given context as analytical tool. With such tool, the nuances of organizational commitment might be better understood, and attitudes and behaviors of organizational members could be better predicted (Meyer \& Herscovitch, 2001).

\section{Conflicts of Interest}

The authors declare no conflicts of interest regarding the publication of this paper.

\section{References}

Alderfer, C. P. (1972). Existence, Relatedness, and Growth: Human Needs in Organizational Settings. New York: Free Press.

Allen, N. J., \& Meyer. J. P. (1990). The Measurement and Antecedents of Affective, Continuance and Normative Commitment to the Organization. Journal of Occupational Psychology, 63, 1-18. https://doi.org/10.1111/j.2044-8325.1990.tb00506.x

Arbuckle, J. L., \& Wothke, W. (1999). AMOS 4.0 User's Guide (pp. 1-429). Chicago, IL: Small Waters Corporation, United States of America.

Aydogdu, S., \& Asikgil, B. (2011). An Empirical Study of the Relationship among Job Satisfaction, Organizational Commitment and Turnover Intention. International Review of Management and Marketing, 1, 43-53.

Barber, A. E., Wesson, M. J., Roberson, Q. M., \& Taylor, M. S. (1999). A Tale of Two Job Markets: Organizational Size and Its Effects on Hiring Practices and Job Search Behavior. Personnel Psychology, 52, 841-867. https://doi.org/10.1111/j.1744-6570.1999.tb00182.x

Baron, J. N., Davis-Blake, A., \& Bielby, W. T. (1986). The Structure of Opportunity: How Promotion Ladders Vary within and among Organizations. Administrative Science Quarterly, 31, 248-273. https://doi.org/10.2307/2392790

Becker, H. S. (1960). Notes on the Concept of Commitment. American Journal of Sociology, 66, 32-40. https://doi.org/10.1086/222820

Bidwell, M., \& Keller, J. R. (2014). Within or Without? How Firms Combine Internal and External Labor Markets to Fill Jobs. Academy of Management Journal, 57, 1035-1055. https://doi.org/10.5465/amj.2012.0119

Brown, S. P., \& Leigh, T. W. (1996). A New Look at Psychological Climate and Its Relationship to Job Involvement, Effort and Performance. Journal of Applied Psychology, 81, 358-368. https://doi.org/10.1037/0021-9010.81.4.358 
Browne, M. W., \& Cudeck, R. (1993). Alternative Ways of Assessing Model Fit. In K. A. Bollen, \& J. S. Long (Eds.), Testing Structural Equation Models (pp. 136-162). Newbury Park, CA: Sage.

Buhrmester, M., Kwang, T., \& Gosling, S. D. (2011). Amazon's Mechanical Turk: A New Source of Inexpensive, Yet High-Quality, Data? Perspectives on Psychological Science, 6, 2-5. https://doi.org/10.1177/1745691610393980

Byrne, B. M. (1994). Structural Equation Modeling with EQS and EQS/Windows. Thousand Oaks, CA: Sage Publications.

Cestone, G., Fumagalli, C., Kramarz, F., \& Pica, G. (2018). Insurance between Firms: The Role of Internal Labor Markets. European Corporate Governance Institute Finance Working Paper No. 489/2016. https://doi.org/10.2139/ssrn.2896921

Chen, C., \& Chiu, S. (2009). The Mediating Role of Job Involvement in the Relationship between Job Characteristics and Organizational Citizenship Behavior. The Journal of Social Psychology, 149, 474-494. https://doi.org/10.3200/SOCP.149.4.474-494

De clercq, D., \& Rius, I. B. (2007) Organizational Commitment in Mexican Small and Medium-Sized Firms: The Role of Work Status, Organizational Climate, and Entrepreneurial Orientation. Journal of Small Business Management, 45, 467-490. https://doi.org/10.1111/j.1540-627X.2007.00223.x

Freund, A. (2005). Commitment and Job Satisfaction as Predictors of Turnover Intentions among Welfare Workers. Administration in Social Work, 29, 5-21. https://doi.org/10.1300/J147v29n02 02

Gittleman, M., Horrigan, M., \& Joyce, M. (1998). Flexible’ Workplace Practices: Evidence from a Nationally Representative Survey. Industrial and Labor Relations Review, 52, 99-115. https://doi.org/10.1177/001979399805200106

Gordon, M. S., \& Thal-Larsen, M. (1969). Employer Policies in a Changing Labor Market. Berkeley, CA: Institute of Industrial Relations, University of California.

Gosling, S. D., Vazire, S., Srivastava, S., \& John, O. P. (2004). Should We Trust Web-Based Studies? A Comparative Analysis of Six Preconceptions about Internet Questionnaires. American Psychologist, 59, 93-104. https://doi.org/10.1037/0003-066X.59.2.93

Hackett, R. D., Lapierre, L. M., \& Hausdorf, P. A. (2001). Understanding the Links between Work Commitment Constructs. Journal of Vocational Behavior, 58, 392-413. https://doi.org/10.1006/jvbe.2000.1776

Harrington, R. J., \& Kendall, K. W. (2007). Uncovering the Interrelationships among Firm Size, Organizational Involvement, Environmental Uncertainty, and Implementation Success. International Journal of Hospitality \& Tourism Administration, 8, 1-23. https://doi.org/10.1300/J149v08n02 01

Herzberg, F., Mausner, B., \& Snyderman, B. B. (1959). The Motivation to Work. New York: John Wiley \& Sons.

Hollister, M. N. (2004). Does Firm Size Matter Anymore? The New Economy and Firm Size Wage Effects. American Sociological Review, 69, 659-676. https://doi.org/10.1177/000312240406900503

Hooper, K., Coughlan, J., \& Mullen, M. R. (2008). Structural Equation Modelling; Guidelines for Determining Model Fit. The Electronic Journal of Business Research Methods, 6, 53-60.

Hu, L. T., \& Bentler, P. M. (1995). Evaluating Model Fit. In R. H. Hoyle (Ed.), Structural Equation Modeling: Concepts, Issues, and Applications (pp. 76-99). Thousand Oaks, CA: Sage.

Ipeirotis, P. (2009). Turker Demographics vs. Internet Demographics. 
https://www.behind-the-enemy-lines.com/2009/03/turker-demographics-vs-internet.html

Islam, T., Khan, S. R., Ahmad, U. N.B.U., Ali, G., Ahmed, I., \& Bowra, Z. A. (2013). Turnover Intentions: The Influence of Perceived Organizational Support and Organizational Commitment. Procedia-Social and Behavioral Sciences, 103, 1238-1242. https://doi.org/10.1016/j.sbspro.2013.10.452

Klein, H. J., Molloy, H. C., \& Cooper, J. T. (2009). Conceptual Foundations: Construct Definitions and Theoretical Representations of Workplace Commitments. In H. J. Klein, T. E. Becker, \& J. P. Meyer (Eds.), Commitment in Organizations: Accumulated Wisdom and New Directions (pp. 3-36). New York: Routledge/Taylor and Francis Group.

Lee, C. H., \& Bruvold, N. T. (2003). Creating Value for Employees: Investment in Employee Development. The International Journal of Human Resource Management, 14, 981-1000. https://doi.org/10.1080/0958519032000106173

Maslow, A. ([1943]2013). A Theory of Human Motivation. Eastford, CT: Martino Fine Books.

Meijaard, J., Brand, M. J., \& Mosselman, M. (2005). Organizational Structure and Performance in Dutch Small Firms. Small Business Economics, 25, 83-96. https://doi.org/10.1007/s11187-005-4259-7

Mendoza, E. C. (2019). The Mediating Role of Job Involvement between Job Satisfaction and Organizational Commitment in a Small and Medium Sized Business Enterprise. International Review of Management and Marketing, 9, 74-81. https://doi.org/10.32479/irmm.8355

Meyer, J. P., \& Allen, N. J. (1991). A Three-Component Conceptualization of Organizational Commitment. Human Resource Management Review, 1, 61-89. https://doi.org/10.1016/1053-4822(91)90011-Z

Meyer, J. P., \& Allen, N. J. (1997). Commitment in the Workplace: Theory, Research, and Application. Thousand Oaks, CA: Sage Publications.

Meyer, J. P., \& Herscovitch, L. (2001). Commitment in the Workplace: Toward the General Model. Human Resource Management Review, 11, 299-326. https://doi.org/10.1016/S1053-4822(00)00053-X

Meyer, J. P., \& Parfyonova, N. M. (2010). Normative Commitment in the Workplace: A Theoretical Analysis and Re-Conceptualization. Human Resources Management Review, 20, 283-294. https://doi.org/10.1016/j.hrmr.2009.09.001

Meyer, J. P., Stanley, D. J., Herscovitch, L., \& Topolnytsky, L. (2002). Affective, Continuance, and Normative Commitment to the Organization: A Meta-Analysis of Antecedents, Correlates, and Consequences. Journal of Vocational Behavior, 61, 20-52. https://doi.org/10.1006/jvbe.2001.1842

Mgedezi, S. M., Toga, R., \& Mjoli, T. Q. (2014). Intrinsic Motivation and Job Involvement on Employee Retention: Case Study-A Selection of Eastern Cape Government Departments. Mediterranean Journal of Social Sciences, 5, 2119-2126. https://doi.org/10.5901/mjss.2014.v5n20p2119

Newmana, A., \& Sheikh, A. Z. (2012). Organizational Commitment in Chinese Small-and-Medium-Sized Enterprises: The Role of Extrinsic, Intrinsic and Social Rewards. The International Journal of Human Resource Management, 23, 349-367. https://doi.org/10.1080/09585192.2011.561229

Nwibere, B. M. (2014). Interactive Relationship between Job Involvement, Job Satisfaction, Organizational Citizenship Behaviour, and Organizational Commitment in Nigerian Universities. International Journal of Management and Sustainability, 3, 321-340.

Ohana, M. (2014). A Multilevel Study of the Relationship between Organizational Justice 
and Affective Commitment: The Moderating Role of Organizational Size and Tenure. Personnel Review, 43, 654-671. https://doi.org/10.1108/PR-05-2013-0073

Oyinlade, A. O. (2018). Organizational Determinants of Job Estrangement in an Organization in the Tourism and Hospitality Industry: A Case Study. Journal of Tourism and Hospitality Management, 6, 115-131. https://doi.org/10.15640/jthm.v6n2a10

Paolacci, G., Chandler, J., \& Ipeirotis, P. G. (2010). Running Experiments on Amazon Mechanical Turk. Judgment and Decision Making, 5, 411-419.

Paullay, I. M., Alliger, G. M., \& Stone-Romero, E. F. (1994). Construct Validation of Two Instruments Designed to Measure Job Involvement and Work Centrality. Journal of Applied Psychology, 79, 224-228. https://doi.org/10.1037/0021-9010.79.2.224

Schumacker, R. E., \& Lomax, R. G. (2004). A Beginner's Guide to Structural Equation Modeling (2nd ed.). Mahwah, NJ: Lawrence Erlbaum Associates. https://doi.org/10.4324/9781410610904

Slichter, S. (1919). The Turnover of Factory Labor. New York: Appleton.

Spector, P. E. (1997). Job Satisfaction: Application, Assessment, Causes, and Consequences. Thousand Oaks, CA: Sage. https://doi.org/10.4135/9781452231549

Steiger, J. H. (2000). Point Estimation, Hypothesis Testing and Interval Estimation Using the RMSEA: Some Comments and a Reply to Hayduk and Glaser. Structural Equation Modeling, 7, 149-162. https://doi.org/10.1207/S15328007SEM0702 1

Teck-Hong, T., \& Yong-Kean, L. (2012). Organizational Commitment as a Moderator of the Effect of Training on Service Performance: An Empirical Study of Small-to-Medium-Sized Enterprises in Malaysia. International Journal of Management, 29, 65-76.

Tsui, A. S., Pearce, J. L., Porter, L. W., \& Tripoli, A. M. (1997). Alternative Approaches to the Employee-Organization Relationship: Does Investment in Employees Pay Off? Academy of Management Journal, 40, 1089-1121. https://doi.org/10.5465/256928

Valaei, N., \& Rezaei, S. (2016). Job Satisfaction and Organizational Commitment: An Empirical Investigation among ICT-SMEs. Management Research Review, 39, 1663-1694. https://doi.org/10.1108/MRR-09-2015-0216

Vroom, V. (1964). Work and Motivation. New York: Wiley Publishers.

Wallace, J. E., \& Kay, F. M. (2009). Are Small Firms More Beautiful or Is Bigger Better? A Study of Compensating Differentials and Law Firm Internal Labor Markets. The Sociological Quarterly, 50, 474-496. https://doi.org/10.1111/j.1533-8525.2009.01149.x

Yang, S., Worden, S., \& Wilson, G. (2004). Sources of Organizational Commitment: The Effects of Internal Labor Markets and Worker Values. Sociological Spectrum, 24, 667-688. https://doi.org/10.1080/02732170490467954 